\title{
Teens Challenged to Re-think the Concept of European Identity in the Museum
}

\author{
Dr. Sofia Trouli ${ }^{1}$ \\ ${ }^{1}$ Department of Preschool Education, University of Crete, Rethymnon, Crete, Greece \\ Correspondence: Sofia Trouli, Department of Preschool Education, University of Crete, Rethymnon, Crete, \\ Greece. Tel: 30-283-107-887. E-mail: arisvi@ hotmail.com
}

$\begin{array}{lcc}\text { Received: July 8, } 2021 & \text { Accepted: August 5, } 2021 & \text { Online Published: August 23, } 2021 \\ \text { doi:10.5539/hes.v11n3p156 } & \text { URL: https://doi.org/10.5539/hes.v11n3p156 }\end{array}$

\begin{abstract}
Museums seek to be places for democratization, inclusion and polyphony. In this paper we present the multimodal conversations of the participating adolescents in the course of a museum pedagogical program in the Museum of Contemporary Art of Crete. The program's topic is Europe and the concept of European identity. Firstly, we prepare the ground through creating an environment of safety and confidence, and next, together with our groups we study the selected artworks, following the routines of 'Artful Thinking', which propose the development of critical thinking through specific questions. This process reinforces reflective thinking and skills of participating in a dialogue. Our aim is to describe and share how a museum through its collections and programs can constitute a space where democratic dialogue and healthy debate are cultivated. In this space, everybody is invited to participate in inquiring, reflecting on self, answering, sharing, with and through the art.
\end{abstract}

Keywords: democratic museum, contemporary art, adolescents

\section{Introduction}

\subsection{Statement of the Problem}

Consider Democracy in school? Consider school within Democracy? These are major enquiries for which we are led to pose new questions, while looking for answers. Is it possible for a museum as a place of informal learning, to contribute in nurturing Democracy in school? -And if so, in what ways? In this paper, we present excerpts from multimodal conversations of the participating adolescents, high school students of Rethymno, of the two-hour museum pedagogical program in the Museum of Contemporary Art of Crete (CCA), "What does Europe mean to me?". The program's focus is Europe and the concept of European identity in particular. Our purpose is to demonstrate but also explore the learning outcomes of how the museum by utilizing its objects, can serve as a means of promoting the Democratic Dialogue, where everyone, young or old, or having any other identity, is welcome to express themselves through art, but also participate in raising questions, seeking answers, inward looking and sharing experiences and ideas, prompted by the works of art.

\subsection{Theoretical Framework}

Nowadays, museums mean to be places of democratization, inclusion and pluralism. They seek to contribute to a critical dialogue regarding the past and the future and to ensure equal access to cultural heritage for all (ICOM, 2019; Sandahl, 2019). At the major conference of the International Council of Museums held in Kyoto in September 2019, although adopting a new definition was not finally approved, the need for the museum to be officially recognised as a key Third Space in society, open, based on systemic principles, inclusive, active, lively, compassionate, with a youthful drive but also with the maturity of a lifetime that has a great deal of experience and can now consider with greater insight into what society and its citizens need in the 21st century, was highlighted (Zeukili, 2019). In our days, quite a few voices are heard regarding whether museums can "save" democracy or not (Toonen, 2019). Often, simple acts such as opening museums to multiple interpretations of their works and cultivating a state of trust, safety, freedom of expression and acceptance of different interpretations and perceptions (Fleming, 2008), are enough to strengthen democracy and statehood.

Even in the case that, democratic museum only means providing incentives to generate a broader conversation by publicizing certain social issues through exhibition policy, then this is sufficient to promote social engagement and participation of citizens, introduction to and contact with different cultures and perspectives or 
perceptions. According to Dahlgren and Hermes (2015), the museum's day-to-day activities can encourage civic culture in six different dimensions: knowledge, values, trust, practices and identity. They also argue that, in a democratic society, public museums' main objective is to support, defend and increase the influence of democratic mechanisms (Nieroba, 2018).

For a museum to be democratic, itself raising questions and seeking answers to issues that are of no interest to the public, is not enough, says Nora Sternfeld (2018; Fornaro \& Kokkonen, 2013). At the same time, she raises the question of how the museum will be able to accommodate its audience in a way that the latter will be willing to engage. The first step is for visitors to bond with the institution; educational programmes can contribute to this.

As Douglas Brent McBride mentions, the modern museum mainly fulfils an affirmative rather than a critical function, offering a refuge of order and relief, to compensate for the lack of civil rights and collective action that characterizes life outside its marble walls (2006).

Chantal Mouffe (2013) argues that, museums as public spaces should be «agonistic», wherein conflicting views are expressed but are not necessarily working on reconciliation. The traditional view suggests finding ways to achieve consensus. The main duty of democracy is not to reach a consensus but to manage dispute, so that it does not lead to civil war or it is not suppressed in an authoritarian way. Even more so, the duty of democracy is to look for ways of communication that make coexistence possible, therefore contributing to freedom, acknowledgement of differences and building tolerance. The likelihood of conflict cannot be eliminated; what we do need to know is how to manage such an occasion (note 1). Additionally, what museums need to do, is to shed light on what the mainstream of power tends to hide and annihilate (Mouffe, 2013; Deufel, 2016), by giving voice to all those who remain silenced within the existing power context (Mouffe, 2013; Deufel, 2016). Natalye Tate (2012) suggested that the Third Place theory (note 2) by Ray Oldenberg (1991) can be adopted to describe and strengthen the role of museums as forces of meaningful civic engagement and social cohesion.

In Greece, Marlen Mouliou (according to Zeukili, 2019) influenced by the above theory, has recently presented museums as the living room (sic) of society, in line with Michael Hickey (2012). This means that the museum and third places overall - although it does not impose on individuals any family or working relationships, it draws upon values, interests, inspiration and domestic practices from the family and work environment. In essence, these are spaces in which community members resort to, in order to enjoy some relaxing time with the company of each other and the occasional small talk. According to Oldeburg (1991), these places can be considered as the heart of a living society and they form the basis of democracy. This function needs to be experienced by people and that is where the museum serves as a means of promoting democratic dialogue.

Third places share four principal qualities: they promote socialization, they encourage members' engagement, they provide comfort or a sense of security, and are accessible to all. Programs developed by museums to foster openness in sharing thoughts and experiences, constructive dialogue, initiatives to promote interculturalism and diversity within societies, empathy and social inclusion of individuals and communities are so many that the reference of examples cannot be condensed into a few lines.

Among the things that a democratic museum has to offer towards building tolerance for others, collective action, coexistence and democratic dialogue, are the museum-pedagogical programs. These programs are much more than just a simple visit or guided tour, since they aim for an active mind set of the participant-visitor, with their senses and prior experiences involved in an experiential approach of the museum reality (Nikonanou, 2010). They also seek to awaken the senses and to fully develop creativity in participants, through the experiential contact with the arts and sciences. Programs are flexible, meaning that each and every time they are adapted to match the age and needs of the participants.

Adolescents are considered one of the most challenging target groups. Yet in museums, adolescents are offered the opportunity to engage in beneficial thought, provoking activities, since museum space provides freedom, safety, but also guidance in cognitive risk-taking if needed, in the way they think and express their views. A museum-pedagogical program provides them with a safe environment to creatively respond to any sad happenings that may occur in their lives. It is confirmed that, especially adolescents, participating in an Art Museum program "come out" of their shell and are more connected to art and to the broader community (Fields, 2016).

In Greece, adolescents (12-18 years of age) do not really take a particular interest in museums. Kouveli's research (2001) concluded that, during the late $90^{\mathrm{s}}$ most adolescents associated museums with acquisition of knowledge and aesthetic appeal, considering them complementary to school, whereas only few referred to its recreational function. This is confirmed by our own experience as well; to make matters clear, following the 
completion of the educational programs, the participating adolescents often confess they initially resented having to visit a museum and did not expect they would have such a pleasant and creative time, or that they would reflect upon their museum experience.

\subsection{Museum of Contemporary Art and the Exhibition}

The Museum of Contemporary Art of Crete is based in the heart of the old historic town of Rethymno. It falls under the Utility of the Municipality of Rethymnon (K.E.DI.R.). It was founded in 1995 when the couple Maria and Mpampis Marangos donated their private collection of contemporary art to the Municipality of Rethymno. The permanent collection of the Museum consists of 650 works. However, the artistic director Maria Marangou and her collaborators have chosen not to have a permanent exhibition. Instead, 180 periodic exhibitions have been arranged in collaboration with organizations in Greece and abroad.

As part of this exhibition policy, the second Festival of artistic photography 2017-2018 was hosted at the CCA, in collaboration with the non-profit organization Medphoto. Medphoto Festival is a meeting of many artistic partners from all over Europe and from the Mediterranean region in particular, in order to cultivate and support a vibrant community of artists and encourage meaningful social dialogue. Members of KOLEKTIV8 argue that, Contemporary photography is here to claim an active role in historical documentation, with Pavlos Fysakis (2017-2018) adding that the images exhibited, do not only capture information but also deepen the view of the situation and offer a great means to reflect (Ioannidis, 2016).

The theme of the $2^{\text {nd }}$ Festival arose from the study of Paul Graham's work "New Europe", which was written during a critical period for Europe, 1988-1992, and was the principal influence of the Festival's main exhibition "Europe, the faces, the territory", curated by Mrs Maria Marangou the CCA Director, and Pavlos Fysakis, photographer and inspirer of the Festival. In particular, in the context of the second Medphoto Festival, CCA hosted a mosaic of photographic projects by 33 artists who attempted to broaden the understanding of the changes taking place on the continent, portraying the old and new face of the people of Europe and outlining European societies the way they are being transformed. They gave prominence to the new anthropogeography moulding day by day, in a land that has been shaped and continues to shape through the coexistence or breach of cultures, religions, languages, races, peoples. Through their projects, artists explore the new identities/dissimilarities that emerge within the rapidly transforming European territory today, as well as whether it makes sense to talk about a single European identity. And if so, how is this identity shaping in our days?

The exhibition "Europe, the faces, the territory" was the occasion for designing and bringing to life the museum-pedagogical program "What does Europe mean to me?". The educational program was implemented in secondary school groups, undergraduate and postgraduate students of the University of Crete as well as groups of adults, during the $2^{\text {nd }}$ Medphoto Festival. It was also presented at the International Conference of the Balkan Museum Network "Meet, See, Do" in 2018 (Trouli, 2018) in an one-hour experiential workshop attended by Jelena Mocevic, program manager of European Heritage Days at the Council of Europe, who invited CCA to participate in the General Assembly of Representatives of the European Heritage Days in Strasbourg 17-19 of October 2018, and to present the workshop as a paradigm of good practice on how to invite young people of Europe to take an interest in the cultural heritage of their country, but also in the concept of European identity. In this context, "What does Europe mean to me?" was introduced to 30 professionals in the field of cultural heritage, from Turkey and Armenia to Ireland and England, and from Greece and Cyprus to Sweden and Moldova, who represented their countries in the European Heritage Days (EHD 2018).

\section{Method}

To start with, it is deemed essential to present the methodology concerning the design of the museum-pedagogical program, and to then proceed with the research methodology of the current work.

\subsection{The Methodology of the Educational Program's Design}

Museum-pedagogical (or otherwise, educational) programs of CCA are 1 to 2.5 hours long and are thematic, based on the selection of works in the exhibition or works in other museums which we study with the support of modern technology, the use of projectors. Participating in the educational programs costs 3 euros per person, whereas in family programs it is only the escorts of minors that need to pay a ticket.

When designing a museum-pedagogical program we mainly adhere to the dialectic method of inquiry, the guided didactic conversation along with the 'Artful Thinking' method which is in certain activities blended with storytelling (reading books, brief heritage interpretation), the inquiry based learning (puzzle, identifying works through their details) and experiential methods (role play, creative writing, dance) (Nikonanou, 2015). What is more, their purpose and targeting are based on the General Learning Outcomes for the evaluation of learning in 
museums as proposed by Hooper and her colleagues (Hooper, 2007, Hooper, Dodd \& Jones, 2007) and are divided into five categories:

\section{Knowledge and Understanding}

2. Skills

3. Attitudes and Values

4. Enjoyment, Inspiration, Creativity

\section{Activity, Behaviour and Progression.}

In the course of the programs, field observations are recorded in relation to General Learning Outcomes, in order to obtain data for their qualitative evaluation past the programs' completion.

Lastly, CCA museum-pedagogical programs consist of four stages:

(1) The stage of relaxation, familiarization with the surrounding space and group acquaintance (approx. 15-30 $\min )$

(2) The stage of introduction to the topic and exploration of prior experiences (approx. $15 \mathrm{~min}$ )

(3) The stage of deepening and reflecting on the topic (approx. $80 \mathrm{~min}$ )

(4) The stage of creative evaluation and emotional discharge (approx. $10 \mathrm{~min}$ ) (Trouli, 2017).

\subsection{Research Method}

Chosen methodology for this work is the descriptive, qualitative method of content analysis of the students' and teachers' discussions. Field notes, recordings of discussions in the research diary following the implementation of the program, as well as brief interviews with the teachers who accompanied the two groups were used as research tools.

The educational program "What does Europe mean to me?" was implemented in two upper secondary school classes of the city of Rethymno, in students 16-17 years of age. One class consisted of 6 students and 2 teachers, who attended the program in 2017-2018 during the $2^{\text {nd }}$ Medphoto Festival. The other class consisted of 20 students and 2 teachers, who attended the program in the year 2018-2019, with the help of a photo projection and printed copies of the works of the 2017 exhibition. School classes were selected on the basis of their participation in European School Programs related to the idea of European Identity. The first class participated in a European Parliament Simulation program, whereas the second one took part in "Ambassadors of the European Parliament 2018-2019" school program. Therefore, members of both groups were familiar with concepts related to European Identity and European Union and its institutions.

Research questions were formed as follows:

- Did the proposed Museum activities contributed to the promotion of democratic dialogue between the groups of adolescents involved, the teachers and the museum educator?

- Were the initial questions broadened in relation to the topic under discussion, i.e. the concept of European Identity in the Museum, and how was this achieved?

For the needs of this article, we felt best to describe program activities in detail, and to quote participants' words, as recorded at each stage.

In stage 1, that of becoming familiar with the group and the surrounding space, we prepared the ground, first by creating a safe and trusting group environment, so that adolescents of both groups get comfortable with expressing their views and feelings, stress-free of any judgement. More specifically, we used breathing techniques for anxiety relief (square breathing, bee breathing), laughter yoga exercises or even a casual stroll in the museum with an alternating walking pace. Groups were then asked to form a perfect circle and quickly shift places with each other, on the basis of external features such as the colour of their clothes or those wearing glasses, or inner characteristics such as hobbies or those whose favourite food is pasta.

These activities aimed at practicing mindfulness (note 3), a deeper awareness of the present, which reduces levels of anxiety, raises emotional awareness, develops self-regulation and sustains a healthy communication in relationships. Afterwards, we introduced ourselves while sitting in a circle, we had paired discussions on the story of our names, and finally, each one introduced someone else to the rest of the attendees (Fig. 1a).

Accounts of this first part were as follows: Student 12 (B): «I did not expect to be able to relax in a museum, play these ice-breaker games and practice relaxation techniques». Student 3 (A): «I thought they would show me around. It was a surprise». Student 18 (B): «I learned the story of my friends' names that I did not know before». 
All in all, during the first stage of the program, communication skills were practiced whereas the students' satisfaction was evident.

In stage 2, we employed 2-3 activities in order to approach the topic 'Europe' and explore the pre-existing knowledge and experiences of our group. Initially, a paper ball went round as a gift from one to another, while repeating that person's name and wishing them 'good morning' in any European language preferred. 'What does Europe mean to me?' was written inside the paper ball (Fig.1b), and a 2-euro coin depicting the myth of Europe was contained (see 1c). The last person to have the paper ball given to opened it up and read the question indicating the coin. Using the brainstorming technique, the answers given were: «continent», «myth», «history», «culture», and «travels». Next, participants noticed the map of Europe and talked about borders, but also Europe outside of Europe. While listening to the Anthem of the European Union and dancing, each group was divided into two subgroups. Each subgroup had to try and shape Europe on the floor out of a tangle, discuss which country they would like to visit, and then pantomime that to the other subgroup, looking to make a right guess (Fig. 1d. 1e.). Through this collaborative and creative activity, the ideas adolescents had for the most publicly recognised countries of Europe were put forward through pantomiming, whether that was well-known monuments such as the Eiffel Tower in France, or positive stereotypical perceptions about the English, such as that they enjoy watching football and having tea.
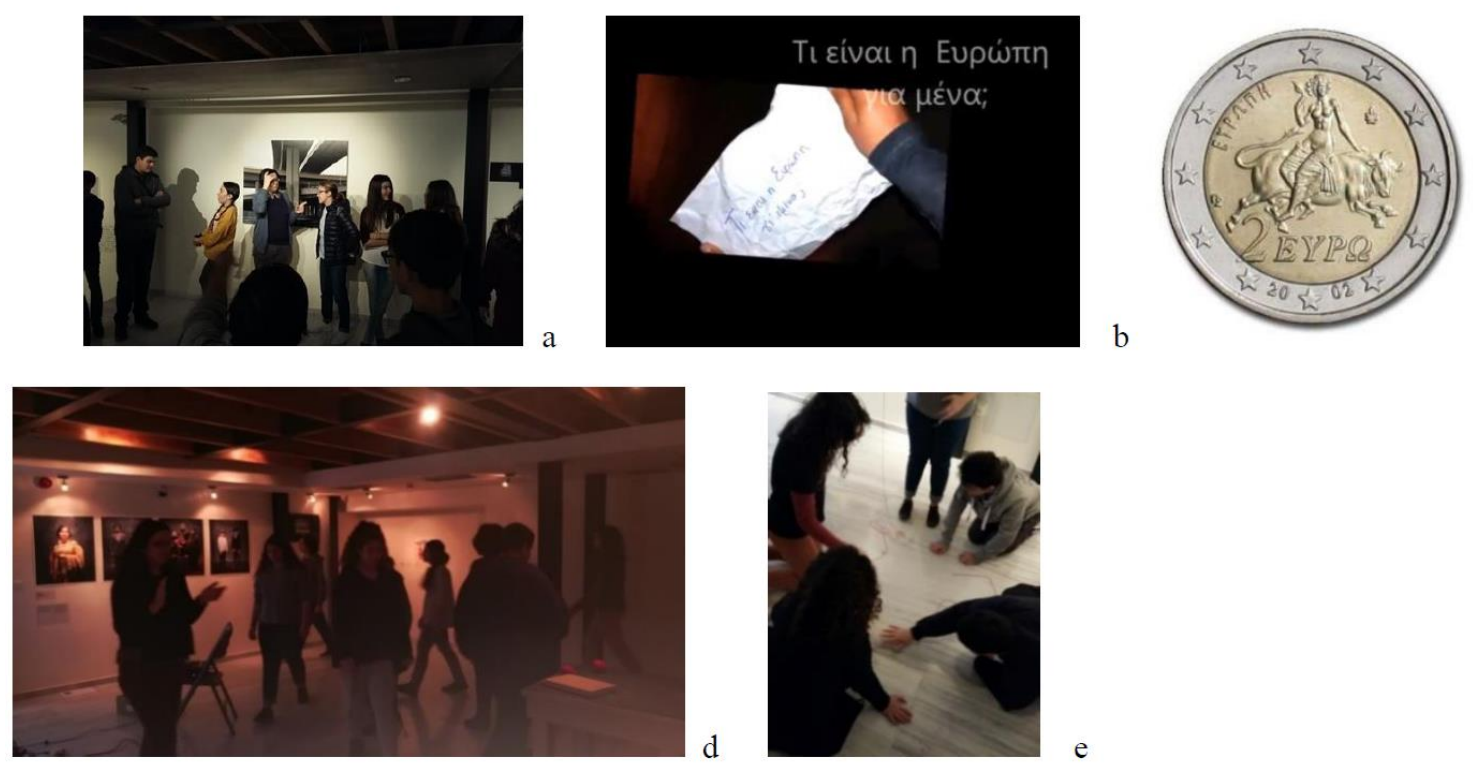

Figures 1. a. b. c. d. e. Moments of the program

CCR Archives $\odot$ Copyright.

In stage 3, that of deepening and reflecting on the topic through studying certain works of the exhibition, the first group of participants was given a guided tour by the museum educator, whereas the second group observed photographs of the works along with slides and copies. One or more routines in the form of questions deriving from the 'Artful Thinking' method or some other creative-experiential activities were combined with each work of art selected. The 'Artful Thinking' method is one of the most well-known approaches to fully utilize art, by the Project Zero program of Harvard Graduate School of Education (Tishman 2017. Project Zero), proposing the cultivation of critical thinking through properly formulated questions that enhance thoughtful thinking and conversation skills.

At first, groups were divided into two subgroups, each with a different colour of candies. The task involved studying the work of Nick Hannes "Mediterranean. The Continuity of Man", which is a recording of parallel realities, a kaleidoscopic portrait of the Mediterranean region through the spirit of times, full of great contrasts and crises, through a role-playing game. More specifically, groups were asked to act out two different roles, that of a European citizen and that of a tourist visiting Europe from another continent. Based on 5 common photos (Fig 2), they were given 10 minutes to discuss 3 positive and 3 negative characteristics of modern Europe. Each group, through one or more representatives, presented the key points of the debate to the rest of us. Among the objectives of this activity was not only the personal but also the participatory observation of the works of art, the 
reflection, the cooperation, the dialogue, the active listening. We shall not dwell on the answers given, but on the fact that all participants had an active part in the discussion, performed the assigned roles, utilizing information from the works but from their previous experience too, and argued for their opinion.
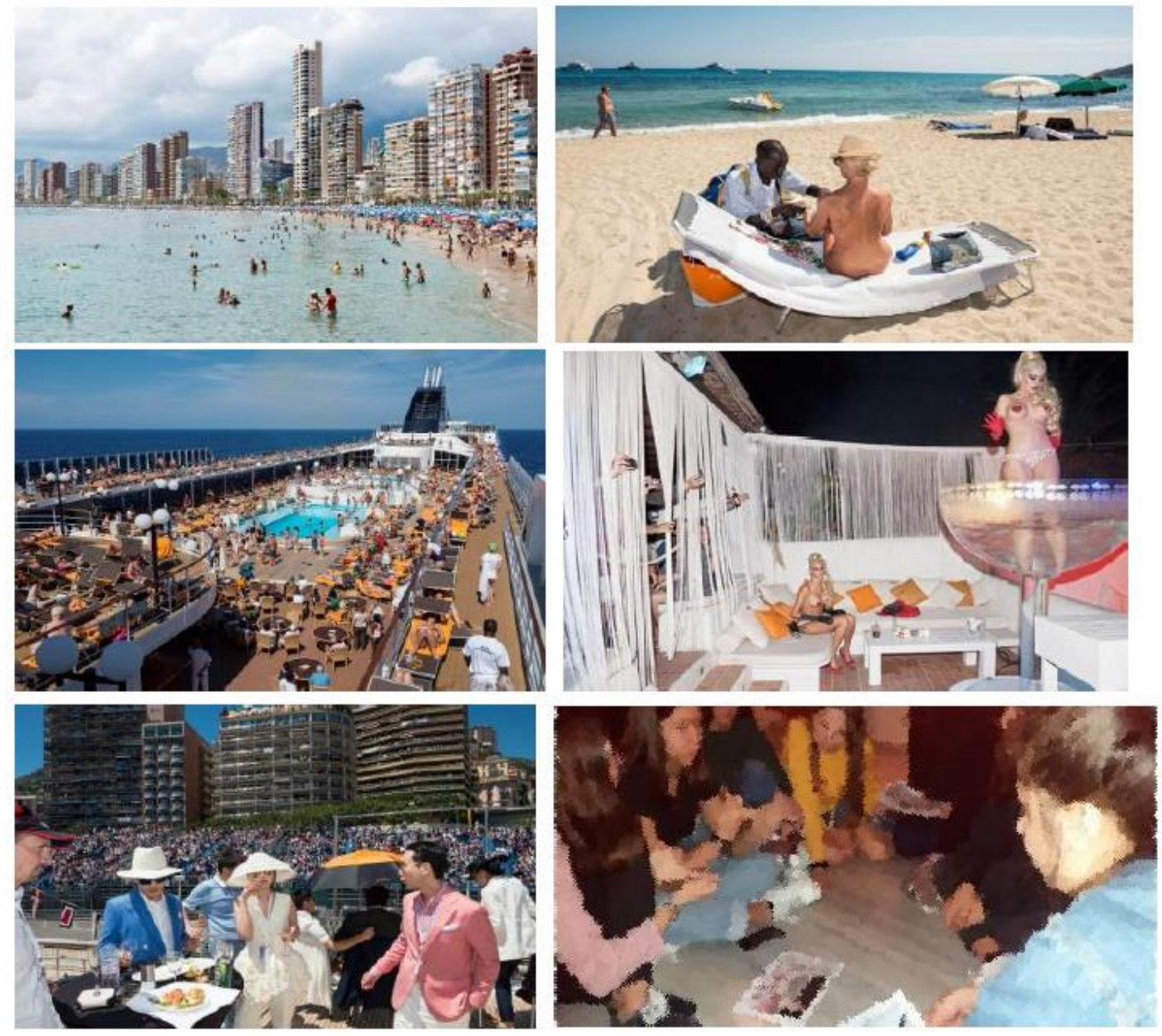

Figures 2. Mediterranean. The Continuity of Man, Nick Hannes (2000-2014)

CCA Archives (๑) Copyright

Up next, all 4 subgroups studied the work of Lewis Bush "A Model Continent" (Fig. 3) on the basis of their previous observations and the following questions: Does it communicate more than one story? Does it evoke any memories? Do any feelings arise? Does the title of the work have much to offer in its interpretation? Through observation and dialogue, the students identified all elements the artist intended to highlight in relation to the past, present and future of Europe. One of the subgroups even decided to write a story about the Odysseus of our times who is a refugee, embarked on a boat named Odyssey and arrived having his hopes for a better life pinned on Europe, but, instead, finds it to be in a "difficult situation" as the dirty stagnant waters in the photo metaphorically indicate. Students also pointed out the various national landmarks-sights of Europe set next to each other, projecting an ideal continent in which the once divided nations now coexist peacefully and harmoniously; yet, students noted places heavily impacted by abandonment and opposition but also logos of sponsoring companies introduced in an unrefined manner in the background. Groups assigned to the role of the tourists stated that, Europe is significant for its monuments but the Europeans citizens themselves do not particularly bother preserving them. Groups assigned to the role of the Europeans pointed out the major discrepancies as well as the social inequalities among the European states nowadays. For several participants of the European subgroup, elements in the photographs brought to mind images of erosion and abandonment, and once informed of the project's title, they expressed their doubts regarding the vision of a united Europe in terms of the equality among member-states; they also expressed their concern regarding the present and the future of a peaceful coexistence and mutual respect for the people of Europe wherein cultural differences are embraced. 

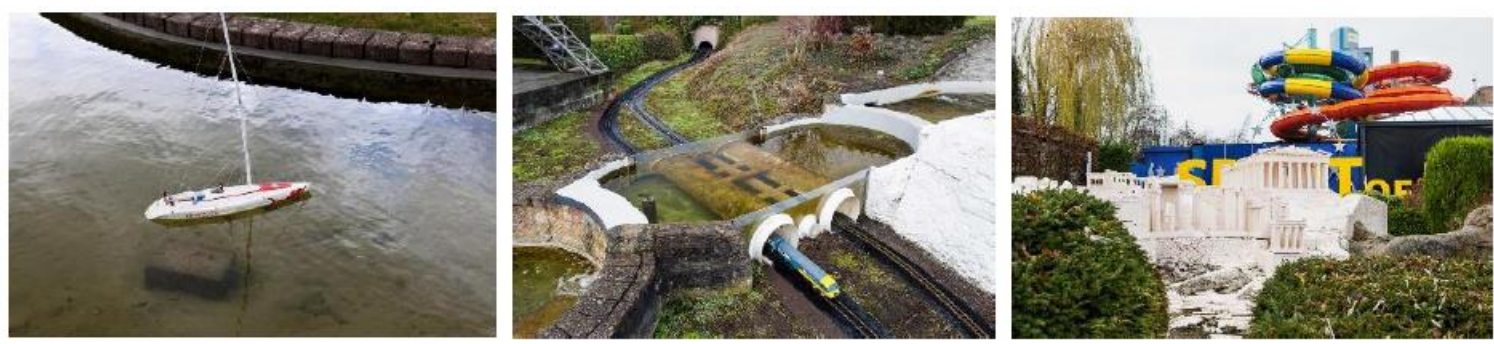

Figures 3. A Model Continent, Lewis Bush (2016)

CCA Archives $\odot$ Copyright

The sequent work the groups studied was "The Castle" by Federico Clavarino (Fig. 4a, 4b). Groups were divided into pairs of two and each one of them observed the work individually. They then shared their views with their partner and announced the conclusions of their discussion to the rest of us. This routine of 'Artful Thinking' is known as 'Think, Pair, Share'. In regard to one specific photograph depicting an older person and a child as if they were about to cross their ways but not finally meeting, some of the pairs identified the difficulties in understanding and the generational gap between middle-aged and young Europeans. Some other pairs saw the initial idea of the European Identity failing, in the adult figure in dark clothes that seems to recede crouching. On the other hand, the little boy, dressed simply in summer-like clothes and in slippers, walking on the wooden train tracks who even although is in danger, he does not seem to give up but to move ahead instead, symbolized the quest for new aspects to be included in the concept of European Identity.

Groups then "met" with "The Buzz Club" (1996-97) by Rineke Dijkstra (Fig. 4c). They were asked to watch the video and say 10 words that came to their minds. Afterwards, participants were urged to dance to the rhythm of the music played in the video for 2-3 minutes, and then think once again of 10 different words, that way basically employing the routine 'Looking 10x2'. Groups pointed out the common characteristics of young people when it comes to fun and entertainment regardless of their national origin. They were then encouraged to conceptualize the notion of identity. In more detail, each adolescent was asked to write down in 6 different pieces of paper 3 words that describe external characteristics, and 3 more words that define inner qualities of their identity. They were given five minutes to complete the task. When they were done writing, they would place the pieces of paper on the floor and we took some time to discuss the different external and internal elements of identity (Fig. 5a). Through this activity they exchanged views on the diverse aspects of their identity and arrived at the conclusion that, just like individual identity is multidimensional, so European identity is a multi-level concept and has various nuances and interpretations.
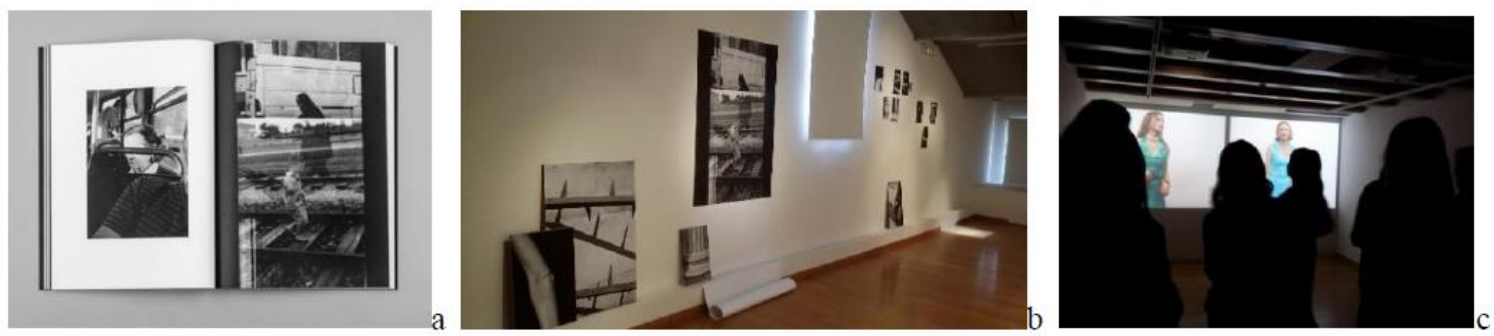

Figures 4. a. b. The Castle, Federico Clavarino. C. In front of the artwork of Rineke Dijkstra CCA Archives $\odot$ Copyright 

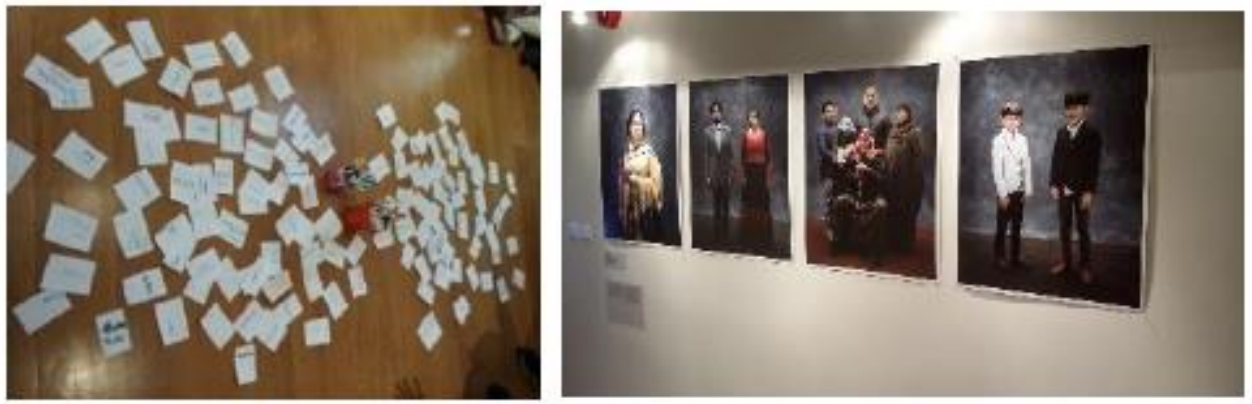

Figures 5. a: Activity about identity's characteristics. 5b: The artwork of Robin Hammond CCA Archives (C) Copyright

Towards further exploring the concept of European Identity we moved on to the work of Thalia Galanopoulou entitled "Points of Authority" (Fig. 6a) and to that of Robin Hammond entitled "The new Europeans: Voices from a changing continent". In order to study both projects, we employed the 'Headlines' routine and additionally asked Is the project posing any questions? Does it narrate a story? What are some of the elements of the project that define identities?

The work of Robin Hammond (fig. 5b), in particular, was approached using the ' 6 Thinking Hats' technique of Edward De Bono (2006). Utilizing the dialectic method of inquiry combined with the educational technique of ' 6 Thinking Hats', adolescents practiced multidimensional thinking and multiple reasoning, since Hammond's photographs were examined through many different aspects. The above technique offers two major advantages; it simplifies thinking, allowing us to engage in one way of thinking at a time, and it also allows for shifts in thinking (De Bono, 2006: 195). Each hat represents a different way of thinking. That is to say, the white hat is neutral and objective; red offers an affective view of the facts; black is the hat of a cautious or even pessimistic way of thinking; yellow represents an optimistic, positive thinking; green is associated with creative thinking and new ideas; and blue organises and connects all previous functions. Participants found this technique interesting, despite the fact that we did not have plenty of time to develop it further. As a matter of fact, they expressed the desire to make the most of it when back in classroom. It was appealing to them because in an effortless, accessible and pleasant way they were able to comprehend how the way of thinking differs depending on each one's character or attitude.
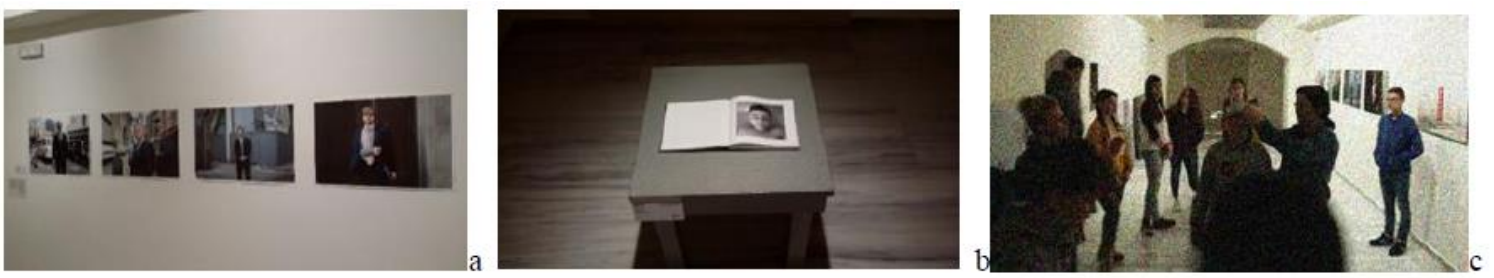

Figures 6. a: The artwork of Thalia Galanopoulou. 6b The artwork of Nikos Pilos. 6c. The "Mine" activity CCR Archives (C) Copyright

The final work of stage 3 was the photobook of Nikos Pilos entitled Trapped, 17/11/15 Abdu Hamid Hamo (Fig. 6b). Groups approached this project through the following questions: What do you see? What do you think it is you are seeing and why? What information is it that you do not have? What is it that you wonder? Browsing through the photobook, starting off with simply observing the elements of the photographs, such as that the photographs were black and white, and that there was a man, seemingly a child, who was naked and had his eyes shut, ended up diving deeper into the pictures and interpreting them as depicting a young child in a mortuary, probably a refugee who did not make it to Europe alive. Following, both groups engaged in a game of empathy concerning the high risk journey that so many people on a daily basis embark on, in search for a safer future in Europe. Participants were scattered across the room, and stood still pretending to be mines in a minefield; one of the participants who was blindfolded, was attempting to safely reach any of the walls in the room within two minutes time, avoiding mines of course. "Mines" had to make a warning sound (beep / clapping / whistling) 
when approached by the teen-traveller. This activity moved the adolescents quite a bit, especially those who adopted the role of the "traveller" (Fig. 6c). Despite being in a safe environment, for a few moments, they too experienced insecurity, the fear of death, but also faith in the only promising idea of escape towards Europe.

In stage 4 of our program, we studied Davide Monteleone's project "One of" (Fig. 7). The photographer inspired by the words of Emperor Claudius in the 1st century AD, writes the following words, completing his photographic work: «My ancestors... encourage me to govern by the same policy of transferring to this city all conspicuous merit, wherever found. And indeed, I know, as facts, that the Julii came from Alba, the Coruncanii from Camerium, the Porcii from Tusculum, and not to inquire too minutely into the past, that new members have been brought into the Senate from Etruria and Lucania and the whole of Italy, that Italy itself was at last extended to the Alps, to the end that not only single persons but entire countries and tribes might be united under our name. We had unshaken peace at home; we prospered in all our foreign relations, in the days when Italy beyond the Po was admitted to share our citizenship... Are we sorry that the Balbi came to us from Spain and other men not less illustrious from Narbon Gaul? Their descendants are still among us, and do not yield to us in patriotism. Everything, Senators, which we now hold to be of the highest antiquity, was once new».

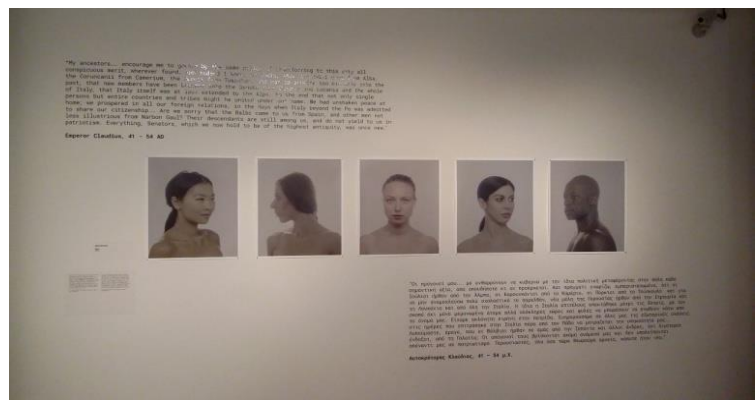

Figure 7. One of, Davide Monteleone (2015)

\section{CCR Archives $\odot$ Copyright}

Since our meeting was coming to an end, we invited participants to reflect upon what the European Identity is after all and how they are feeling, taking this final project (pictures and text) as well as what we discussed throughout the program into consideration. Few thoughts coming from adolescents in group one of the program "What does Europe mean to me?" are quoted below:

Alexandra: «They were called Roman citizens because they once shared something. Maybe it was once economic privileges, economic relations, later on it was Christianity... In any case, there are common focal points and somewhere along the line, everyone retains their uniqueness. And I think we talk about inflows of other nationalities and that the European identity is being altered, but I consider that to be part of the social and historical evolution. Therefore, if blending is among the demands of our times, it shall be done, and populations will preserve their own qualities and they will create a common consciousness for all».

Ioanna: «I don't know, I'm a little bit confused. So far I only used to acknowledge the positive aspects of Europe, the development, the studies. And all of a sudden, now, after this program, the downsides caught my attention too. Personally, I'm now beginning to consider both the good and the bad aspects. And this exhibition presents both sides and I am somehow concerned and confused».

Myrto: «I agree with Ioanna. I am troubled. I am concerned about some issues relating to European identity and Europe. At the same time, I feel lucky to belong to the collective that Europe embodies. I'm worried though».

Yiannis: «What stuck with me is that Europe has many sides. There are so very different people in Europe».

Eva: «There are different people, different cultures, different experiences, and different memories. In Europe, they all come together, become one, it's a starting point for people to meet each other and share common experiences, get to know each other and share things in common».

Maria: «Maybe Europe has no borders. It's like a melting pot. It is good that this process is being photographed in order to remain in history».

Finally, to unwind, we once again employed breathing or relaxation techniques used in theatre games. In "What does Europe mean to me?" we sat in a circle and played the balloon game. Everyone has their head down (looking at the floor). At the animator's signal, e.g., «Heads up», they raise their heads up to catch someone 
else's eye. If this happens at the first attempt (rather than looking to find each other), them two both make the sound of a balloon deflating and then sit down. This is repeated until one or two are left standing in the circle.

Few adolescents also wrote a note in the Museum's book before departing (Fig. 8a):

(M): A day in my life I'll never forget!

(X.O.1): A day I met important people that I'll never forget! A symbolic and significant place, art brings us together (X.O.)

(X.O.2): An amazing guided tour, different than any other, one with significance!

(X.O.3): A guided tour in this museum, for which I am proud to have in my town. Beautiful, creative exhibits.

(X.O.4): Art is the lie that allows us to realize the truth, to quote Pablo Picasso.

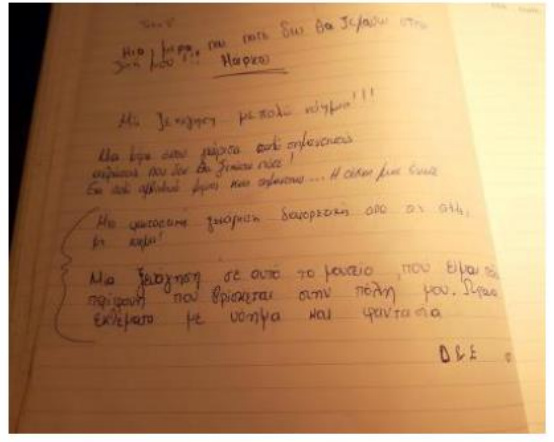

a

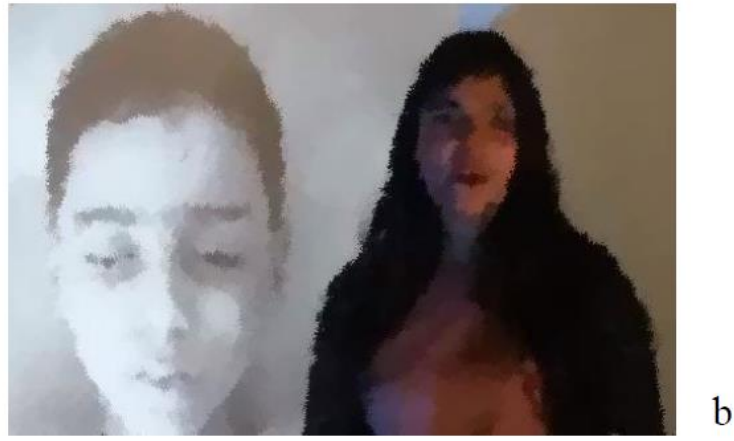

Figures 8. a: From the museum's book of visitors. 8b Video creation

CCR Archives $\odot$ Copyright

Prior to departing from the Museum, adolescents of the second group shot short videos, in which they described the Europe they dream of living in. They chose a work of the exhibition at the time, the "Poetry of Memory", which somewhat matched their thoughts, or one of the works on Europe that we had studied through the projector, and wished for a Europe with open horizons for all, without stereotypes, without terrorism, a Europe in which they would feel safe, without conflicts, where there is plenty of opportunities for young people, for women's rights, without war, a place where social inequalities are eliminated and no one is deprived of their future (Fig 8b).

The words of a teacher of group one, highlighted the importance of the visit in deepening adolescents' reflection upon such topics, which was initially motivated by participating in the European Parliament's School Simulation program. In addition, past the completion of the program, one of the teachers in the second group found that students were delighted but also touched by sensitive issues, such as the challenges refugees face, the poverty as well as the environment. It was a unique experience that led in the adolescents shooting the videos, in an attempt to pass on a message on the importance of Europe, being members of the "Ambassadors of the European Parliament 2018-2019" program. To conclude, the program was a unique and memorable experience for everyone, beyond any expectations.

\section{Discussion}

Contemporary art works, inspired by social issues that affect modern society may serve as an occasion for cultivating democratic dialogue. After all, according to Mrs Maria Marangou the artistic director of CCA, art throughout the ages, manifests the challenges any society faces. Each and every period in time is characterized by its own particular problems and art serves as a means to provide answers to them (Ioannidis, 2016).

As evidenced by the examples of the Museum of Contemporary Art of Crete that we elaborated previously, museums can function as public spaces for cultivating democratic dialogue not only through their works but also through the activities they propose, through providing a safe learning environment for interaction and construction of meaning. They can cultivate dialogue, empathy, active listening, inquiring, expression of emotions and ideas, essentially all those components of democracy in a school and of school within a democracy, because, as stated by the teachers in one of the groups, «art penetrates the harsh reality and touches the hearts of children» (Kofopoulou et al., 2017).

Attempting to answer the research questions, whether the proposed Museum activities contributed to the 
promotion of democratic dialogue between the groups of adolescents involved, the teachers and the museum educator, and whether the initial questions were broadened in relation to the topic under discussion, i.e. the concept of European Identity in the Museum, and how was that achieved, we come to the following conclusions: Through the program "What does Europe mean to me?" the participating adolescents contemplated both as a group and as individuals and delved more deeply into issues related to the European Union, but also, into the multiple features of the concept of European Identity. A common finding of both educational groups was that, despite having extensively deal with Europe related issues at school, the Museum space and their "meeting" with the works of art encouraged them to reflect upon these issues and to conceive notions they had not previously thought of, such as the new realities emerging by the migrant and refugee inflows in Europe and the timelessness of this constant movement of the populations, but also to consider the positive as well as the negative aspects of a common European identity. Some adolescents admitted that the works of the exhibition, motivated them to reflect on issues that they themselves take for granted, such as the right to security, education, games and entertainment, or the very value and importance of a united Europe.

Regarding evaluation based on the General Learning Outcomes, adolescents who participated in the program made progress in all 5 categories. That is to say, at the level of Knowledge and Understanding, they broadened and deepened their insight on issues concerning Europe. Additionally, at the Skills level they worked together to complete the activities, they argued for their views and interpretations. At the level of Attitudes and Values, they appreciated the social pluralism of the European identities and became aware of issues they had not previously considered in relation to Europe, such as interculturalism, the timelessness of migration and refugee phenomena. What is more, they did not expect having such a good time in a museum. Adolescents, who visit museums as part of their teaching activities, are biased towards a potentially boring extension of the learning process, just as those who participated in the research program were. They generally admittedly having a good time; they laughed, danced, got inspired and created their own works, as in the case of the videos. They also grew as individuals by exchanging ideas in a safe and conducive environment that provided them with information, but also offered experiences relevant to their own lives. Last but not least, they gained incentive to get more involved in the European school programs they already participated in, and to do a more in-depth research on European issues.

All in all, the need to emphasize the importance of visits in museums with groups of adolescents is imperative, ultimately aiming at promoting a state awareness and orienting them towards the essential qualities of an active citizen, such as critical thinking, active listening, participation in dialogue, but also decision-making, raising social responsibility and activism, as a way of addressing the problems that people in our times face.

\section{Acknowledgment}

Throughout the research and my work in the museum of Contemporary Art of Crete I have received a great deal of support and assistance. I would like to thank the director of the Museum, Maria Marangou and my other colleagues, Kostas Xristidis, Katerina Kouyioumoutzi, Ntina Lebidaki and Giorgos Anifandakis.

\section{References}

De Bono, E. (2006). The six thinking hats. Translation. G. Barouxis. Athens: Alkyon Editions. (In Greek)

Dahlgren, P., \& Hermes, J. (2015). The Democratic Horizons of the Museum. Citizenship and Culture. In A. Witcomb \& K. Message (Eds.), The International Handbooks of Museum Studies: Museum Theory. New York: John Wiley \& Sons, Ltd. Published. https://doi.org/10.1002/9781118829059.wbihms107

Deufel, N. (2016). Agonistic Interpretation. Retrieved from https://nicoledeufel.com/2016/11/03/agonistic-interpretation/

Fields, D. J. (2016). Teening the museum: an adaptable teen program for art and history museums. New York: Bank Street College of Education. Retrieved from http://educate.bankstreet.edu/independent-studies/176

Fleming, D. (2008). The democratic museum. Keynote speech. Liverpool MA conference. Retrieved from http://www.museumsassociation.org/download?id=17446

Fornaro, S., \& Laura, K. (2013). Reflections from the Floor. In K. Kaitavuori, N. Sternfeld \& L. Kokkonen (Eds.), It's all Mediating: Outlining and Incorporating the Roles of Curating and Education in the Exhibition Context. Finnish Association foe Museum Education Pedaali. Cambridge Scholars Publishing. Newcastle.

Fraser, N. (1992). Rethinking the Public Sphere: A Contribution to the Critique of Actually Existing Democracy. In C. Calhoun (Ed.), Habermas and Public Sphere (pp. 132-136). Cambridge: MIT Press.

Hickey, M. (2012). In praise of (Loud, Stinky) Bars. Shelterforce. The voice of community development. 
Retrieved from https://shelterforce.org/2012/05/24/in_praise_of_loud_stinky_bars

Hooper-Greenhill, E. (2007). Museums and education: purpose, pedagogy, performance. London: Routledge. https://doi.org/10.4324/9780203937525

Hooper-Greenhill, E., Dodd, E., \& Moussouri, T. (2007). Measuring the Outcomes and Impact Learning in Museums, Libraries and Archives. University of Leicester' RCMG.

ICOM. (2019). The Extraordinary General Conference postpones the vote on a new museum definition. Retrieved from https://icom.museum/en/news/the-extraordinary-general-conference-pospones-the-vote-on-a -new-museum-definition/

Ioannidis, S. (2016). «Medphoto»: Information that becomes art. Newspaper Kathimerini. Retrieved from https://www.kathimerini.gr/861215/article/politismos/eikastika/medphoto-h-plhroforia-poy-ginetai-texnh

Kouveli, A. (2001). The student and the museum: Experiences and perceptions. Social Research Inspection, 104-105, 63-87. Retrieved from https://ejournals.epublishing.ekt.gr/index.php/ekke/article/viewFile/8819/9041.pdf (In Greek)

Kouveli, A. (2000). The students' relationship with the museum. Theoretical approach, research in Athens and Ikaria, educational programs. Athens. EKKE. (In Greek)

Kritikou, A. (2019). Mindfulness | Benefits to students' school life. Nice life. Retrieved from https://www.omorfizoi.gr/ensyneiditotita-mindfulness-ofeli-sti-scholiki-zoi-ton-mathiton/ (In Greek)

Kosti, K. (2014). Museum and Past: Suggestions for Applications in Secondary Education. Archeology \& Arts, Tribute: Museums and museology in modern society. New challenges, new relationships, Part 15th. Archaeology and Arts. Retrieved from https://www.archaiologia.gr/blog/2015/02/16/ (In Greek)

Kofopoulou, I., Renieri, E., \& Xristoforaki, M. (2017). The Experimental High School at the Museum of Contemporary Art. Rethemnos. Retrieved from https://rethemnosnews.gr/2017/03/ (In Greek)

Medphoto. (2016). Medphoto Festival 2016. Borders and Crossroads. Crete Rethimno. Retrieved from https://medphoto.gr/el/home-gr/

Medphoto. (2017-2018). Medphoto Festival 2017-2018. Europe: The faces and the space. Retrieved from https://medphoto.gr/el/home-default-2/

Mouffe, C. (2010). From competitive politics to a competitive public space. Retrieved from https://www.republic.gr/?p=2474

Mouffe, C. (2013). Agonistics. Thinking the World Politcally. London: Verso.

Nieroba, E. (2018). Museums change lives. The role of museum in the creation of the democratic Public Sphere. Studia migracyjne-Przeglad Poloniijny, 2(168), 229-238. https://doi.org/10.4467/25444972SMPP.18.027.9153

Nikonanou, N. (2010). Museumpedagogy. From theory to practice. Athens: Patakis editions. (In Greek)

Nikonanou, N. (Ed.). (2015). Museum learning and experience in the 21st century. Hellenic Academic Ebooks, National technical University of Athens. (In Greek)

Oldenberg, R. (1991). The Great good place: Cafes, coffee shops, community centers, Generals Stores, Bars, Hangouts, and how they get you through the Day. Paragon House Publishers.

Sandahl, J. (2019). The Museum Definition as the Backbone of ICOM. Museum International, 71, 1-2. https://doi.org/10.1080/13500775.2019.1638019

Sternfeld, N. (2018). Das radikaldemokratische Museum. Berlin: DeGruyter.

Tate, B. N. (2012). Museums as Third Places or What?. Museum \& Social Issues, 7(7), 269-283. https://doi.org/10.1179/msi.2012.7.2.269

Tishman, S. (2017). Slow Looking: The Art and Practice of Learning Through Observation. New York, NY: Abingdon, Oxon: Routledge. https://doi.org/10.4324/9781315283814

Toonen, S. (2019). Can museums save European Democracy?. Retrieved from https://magazine.areweeurope.com/stories/elections-issue/stella-toonen-museums-democracy

Trouli, S. (2017). Brief introduction to museum pedagogy and its utilization techniques by teachers. In K. Karras (Ed.), Issues of Contemporary Pedagogy, Teaching Theory and Practice (pp. 261-284). University of Crete. School of Education. Department of Primary Education. KEMEIEDE. Pedagogical and Teaching Adequacy 
Program. (In Greek)

Trouli, S. (2017). Discussing the refugee crisis, facing borders and crossroads. In C. Angelini (Ed.), Best Practice 6. A tool to improve museum education internationally (pp. 101-108). Edizione Nuova Cultura: Roma. Retrieved from https://drive.google.com/file/d/1bn3kgNlslkN5d70nsPIJxPZfdKaeB5f1/view?usp=sharing

Trouli, S., \& Konstantinos, C. (2018). Talking about refugees in front of borders and crossroads. In K. Basil., K. Ioan., K. Aik., K. Styl., P. Georg., \& S. Androniki (Eds.), Proceedings of the 2nd Panhellenic Conference "Education and Culture: Relationships and Perspectives" Heraklion 2018 (pp. 401-412). Regional Primary and Secondary Directorate of Crete. (In Greek)

Zeukili, D. (2019). How can museums emerge from the crisis and become the living room of society? Athinorama. Retrieved from https://www.athinorama.gr/cityvibe/article/pos_mporoun_na_bgoun_ta_mouseia_apo_tin_krisi_kai_na_gin oun_to_living_room_tis_koinonias-2538648.html (In Greek)

\section{Notes}

Note 1 . That simply translates to acknowledging the legitimacy of the claims of the Other; We acknowledge that we have a right to "agree to disagree" and that we may not be able to reconcile our views. This form of expression is compatible with a democratic society (Mouffe, 2013).

Note 2. In 1991 the sociologist Ray Oldenburg, in his book The Great Good Place, introduced the term "Third Place" to define those spaces which, other that the first and second place, personal and working respectively, play a significant role in society by empowering local communities and democratic institutions. Third places promote social equality and active citizenship, where citizens can share practices of socializing, ideas and experiences, therefore offering psychological empowerment at the individual and societal level (Zeukili, 2019, Oldenburg 1991).

Note 3. Mindfulness is the psychological process that brings our attention, our awareness to experiences lived at present moment. The benefits of mindfulness practices are becoming increasingly valued in educational organisations around the world, including nursery and primary schools. This has been reported as part of a meditative shift in education, emerging since the turn of the millennium. The application of mindfulness in schools aims at calming and relaxing students as well as teachers, to enhance compassion and empathy towards others. An additional advantage of mindfulness in education is the reduction of stress in students. Mindfulness studies in children continue to increase (Kritikou, 2019).

\section{Copyrights}

Copyright for this article is retained by the author(s), with first publication rights granted to the journal.

This is an open-access article distributed under the terms and conditions of the Creative Commons Attribution license (http://creativecommons.org/licenses/by/4.0/). 